Colloquia Litteraria

UKSW

ИГОРЬ БЕЛОВ

$2 / 2017$

\title{
СБОРНИК ПОЛЬСКОЙ ПОЭЗИИ В РУССКИХ ПЕРЕВОДАХ, СОСТАВЛЕННЫЙ ЮЗЕФОМ ЧАПСКИМ В 1942 ГОДУ: ИСТОРИЯ ВОЗНИКНОВЕНИЯ, АНАЛИЗ ПЕРЕВОДОВ
}

Казалось бы, в истории переводов польской поэзии на русский язык уже почти не осталось «белых пятен». Однако машинописный текст «Сборника польских поэтов», составленного Юзефом Чапским в 1942 году в Ташкенте для публикации в издательстве «Советский писатель», свидетельствует об обратном. Эта небольшая антология, включающая 34 стихотворения ведущих польских поэтов времен Второй мировой войны (в частности, Казимежа Вежинского, Марии Павликовской-Ясножевской, Владислава Броневского, Антония Слонимского, Станислава Балинского) в переводах Марка Живова, Анны Ахматовой, Николая Ушакова, Абрама Эфроса и других русских поэтов-переводчиков, находившихся тогда в эвакуации, так и не была напечатана, десятки лет пролежала в архиве и была обнаружена совсем недавно. Мне представляется, что данный сборник, обещавший стать важным и неординарным событием в хронике польско-российских литературных связей, довольно ярко иллюстрирует не только состояние русского поэтического перевода с польского языка во время Второй мировой войны, но и помогает сделать ряд важных выводов относительно главных трудностей и проблем, с которыми русские переводчики польской поэзии сталкивались тогда и продолжают сталкиваться по сей день. Именно эти аспекты являются главным предметом рассмотрения в данной статье, однако сначала скажу несколько слов об истории создания антологии. 
1.

Юзеф Чапский оказался в Ташкенте весной 1942 года. Еще в 1939 году Чапский попал в советский плен, чудом избежал расстрела в Катыни, в 1941 году вступил в польскую армию, сформированную на территории СССР и в 1942 году стал пресс-секретарем штаба армии генерала Андерса под Ташкентом, возглавив отдел пропаганды и просвещения. Штаб армии Андерса располагался в городе Янги-Юль, где Чапский познакомился с писателем Алексеем Толстым. У обоих возникла идея издать сборник современной польской военной поэзии в русских переводах, а для того, чтобы вдохновить на участие в подготовке сборника других русских литераторов, Толстой в начале мая 1942 года организовал в своем ташкентском доме встречу Юзефа Чапского с русскими поэтами и переводчиками. На встрече присутствовал Александр Тихонов, главный редактор издательства «Советский писатель», которое собиралось выпустить сборник. Чапский читал стихи польских поэтов-эмигрантов, которые, как он впоследствии вспоминал, произвели на собравшихся сильнейшее впечатление, в особенности на Анну Ахматову. Существует легенда о том, что свое загадочное стихотворение «В ту ночь мы сошли друг от друга с ума...» поэтесса написала под влиянием встречи с Чапским.

Осенью 1942 года «Сборник польских поэтов» был готов к печати, однако книга так никогда и не вышла. Формальным поводом такого решения издательства стали не слишком положительные отзывы двух рецензентов. Литературный критик Евгения Книпович дала книге отрицательную оценку, написав, что «идейно-политическое настроение сборника скорее правительственное, чем народное, что патриотизм его - ограниченный, что звучание многих стихов не чуждо декаданса». Что ж, отзыв вполне характерный для официальной литературной критики сталинской эпохи; рецензент при этом даже и не скрывает, что о современной польской поэзии не знает практически ничего. Другой рецензент, поэт-переводчик и секретарь Союза писателей Петр Скосырев был менее категоричен - по его мнению, 
«настроения широких кругов интеллигенции Польши в нем [сборнике - И.Б.] нашли весьма убедительное выражение». При этом Скосырев сетовал, что гнев и горечь авторов антологии носят пассивный характер, отмечал, как и Книпович, низкое качество некоторых переводов, однако подчеркивал, что «сборник бесспорно может быть интересен как документ. Но следует переформировать его».

Правда, не исключено, что издание сборника не состоялось по политическим мотивам. К осени 1942 года армия Андерса покинула территорию Советского Союза, оказавшись в Иране, чтобы затем сражаться на стороне союзников. Отношения между СССР и польским правительством в изгнании сделались напряженными, так что с пропагандистской точки зрения необходимости в издании книги на тот момент уже не было. Машинопись сборника долгие десятилетия пролежала в Российском государственном архиве литературы и искусства (РГАЛИ).

2.

Меня, как переводчика, этот сборник интересует в первую очередь как довольно яркая иллюстрация основных аспектов перевода польской поэзии XX века, а также тех вызовов и сложностей, с которыми сталкивались тогда русские переводчики польской поэзии. Как и в любой антологии, в сборнике есть очень удачные (а порой и просто гениальные) переводы - но есть и ошибки, творческие ляпы, вплоть до откровенных переводческих провалов.

Попробуем же проанализировать содержание антологии, исходя из основных критериев качества перевода.

Начнем с того, что является основой каждого стихотворения - с ритма. Как известно, одна из сложностей поэтического перевода связана с передачей и сохранением ритмического и интонационного своеобразия оригинала. Сложность здесь заключается в том, что в каждой литературе за тем или иным стихотворным метром закреплена определенная традиция, которую Михаил Гаспаров называл «семантическим ореолом 
стихотворного размера». По его мнению, «связь между метром и смыслом есть связь органическая» ${ }^{1}$.

В нашем случае русский переводчик сталкивается с двумя сложностями: разный характер ударения в русском и польском языках и польские литературные традиции в области ритма. В обсуждаемом сборнике переводчики имели дело с двумя метрическими системами: силлабической и силлабо-тонической. К примеру, представленные в антологии три стихотворения Марии Палвиковской-Ясножевской («Весна этого года», «Рифмы» и «Нашей вербе»), переведенные Александром Кочетковым, написаны силлабическим стихом:

Rymy, zabawko moja, szkatułko otwarta,

Pełna korali, wstążek, błyszczących kamieni;

Jak sroka gromadziłam was; najmilsze chwile Spędzałam, przesypując was z ręki do ręki...

$(« R y m y »)$

Разумеется, перед нами классический польский тринадцатисложник. Отсутствие регулярности в расположении ударных и безударных слогов приводит к тому, что русское ухо не чувствует упорядоченности, которая достигается благодаря одному и тому же количеству слогов. Некоторые начинающие переводчики вообще воспринимают такие стихи как верлибр, верлибром их и переводят, чего ни в коем случае нельзя делать. Известный российский филолог и переводчик Денис Пелихов считает, что существуют два способа перевести такие стихи на русский язык ${ }^{2}$ Первый - это использовать традиционный русский тринадцатисложник, господствовавший в русской поэзии в XVII-XVIII веках, до реформы Тредиаковского-Ломоносова, которые ввели силлабо-тоническую систему. Однако

\footnotetext{
1 Михаил Л. Гаспаров, Метр и смысл, Москва 2012, с. 3-10.

2 Денис А. Пелихов, Особенности перевода поэзии Чеслава Милоша, в: Наука ЮУрГУ: материалы 66-й научной конференции Секции социальногуманитарных наук, Челябинск 2014, с. 392.
} 
применительно к стихам, написанным в XX веке такой способ не очень-то годится, поскольку вместо польской военной поэзии мы получим Антиоха Кантемира: «Уме недозрелый, плод недолгой науки! / Покойся, не понуждай к перу мои руки...». И стихи начнут звучать архаично, а то и комично. Поэтому переводчик, как в случае Кочеткова, идет по второму пути: переводит стихи Марии Палвиковской-Ясножевской, регулярным белым стихом, «русифицируя» метр стиха и упорядочивая в нем расположение ударных и безударных слогов:

Мои игрушки - рифмы, - полная шкатулка

кораллов, ленточек, сверкающих каменьев, -

Я вас копила, как сорока. Я не знала

иной игры, как вас пересыпать меж пальцев...

(перевод Александра Кочеткова)

Думаю, есть еще третий вариант - переводить стихи подобного типа российским дольником, размером, блестяще использованным Пушкиным в «Песнях западных славян», снискавшим популярность в эпоху Серебряного века (сам термин «дольник» был введен Валерием Брюсовым), а ныне прочно ассоциирующися с метром стихов Иосифа Бродского. Дольник - это разновидность тонического стиха, в котором совпадает только число ударных слогов, безударные же слоги являются величиной переменной. Как мне кажется, русский дольник лучше «имитирует» звучание польского стиха, да и у русского читателя он, пусть и подсознательно, ассоциируется с иностранной просодией. В связи с тем, что у дольника куда более расшатанный ритм, нежели у русского регулярного силлабо-тонического стиха, русское ухо невольно «маркирует» стихотворение, написанное дольником, как стихотворение, представляющее из себя перевод с неизвестного языка. Характерно, что многие русские поэты часто прибегали к дольнику, когда им хотелось заговорить языком стилизации, имитировать речь вымышленного зарубежного поэта, выйти за пределы своего лирического «я»: примером тому могут служить уже упомянутые «Песни западных славян» 
Пушкина, «Александрийские песни» Михаила Кузмина и «Абиссинские песни» Николая Гумилева:

Раз услышал бедный абиссинец,

Что далеко на севере, в Каире,

Занзибарские девушки пляшут

И любовь продают за деньги ${ }^{3}$.

(Николай Гумилев, «Занзибарские девушки»)

Впрочем, в обсуждаемой нами антологии дольник у переводчиков практически не представлен - в годы войны он был не слишком употребим.

Как я уже говорил, ссылаясь на Гаспарова, ритм и размер очень часто диктуют стихотворению не только настроение и интонацию, но и смысл. Именно поэтому вряд ли можно признать удачным решением изменение переводчиком Абрамом Эфросом ритма стихотворения «Ostatnia melodia 1940» («Последняя мелодия 1940») Станислава Балинского. Здесь ближе к ритму оригинала был бы более сдержанный трехстопный амфибрахий или тот же дольник, у Эфроса же - избитый четырехстопный ямб, который тут же создает романсовую интонацию, еще и благодаря безнадежно устаревшим даже для середины прошлого века обротам вроде «подросток милый» (в оригинале «miła francuska dziewczyna», то есть «милая французская девушка») и «лавка чар» (в оригинале «sklep, pełen zjaw i mar» - «магазин, полный призраков»). Точно так же обстоят дела с переводом стихотворения Владислава Броневского «Bagnet na broń» (в переводе Марка Живова - «Примкнуть штыки»), написанного в 1939 году. Переводчик «размазывает» ритм уже в первой строке («Kiedy przyjdą podpalić dom» - «Когда придут, чтобы сжечь твой дом»), что делает перевод несколько рыхлым, хотя ритм этого стихотворения Броневского абсолютно совпадает с маршевым, агрессивным ритмом знаменитого стихотворения Константина

3 Николай С. Гумилев, Полное собрание сочинений в 10 томах, Том. 2: Стихотворения. Поэмы (1910-1913), Москва 2007, с. 15. 
Симонова «Если дорог тебе твой дом...» со знаменитым рефреном «Сколько раз увидишь его, столько раз его убей», написанного тремя годами позже, в 1942 году. Возможно, переводчик не захотел оказаться в плену заразительной для того времени симоновской интонации, что его в конечном итоге и подвело. А стихотворение Казимежа Вежинского «Zstąp, duchu mocy» (в переводе «Внемли, всемогущий») - это молитва, произносимая отрывисто, чуть ли не сгороговоркой, словно во время марша или перед боем, когда нет времени громоздить цветастые строфы. У переводчика же Светланы Сомовой получился не столько перевод, сколько стихотворение «по мотивам» (здесь можно вспомнить некоторые стихотворения Андрея Вознесенского, написанные «на мотив» американских поэтов Уильяма Джея Смита и Роберта Лоуэлла, которые, впрочем, многими и впервую очередь самим переводчиком! - расцениваются как полноценные, хоть и вольные, переводы, а не самостоятельные произведения). Даже тот, кто не знает польского, легко уловит, сравнивая перевод с оригиналом, что перед нами два разных текста, объединенных общей тематикой:

Patrz:

Nadludzkiej poddani próbie, Tylekroć zaprawieni w cierpieniu, Stawimy czoło idącej zgubie, Walczymy o siebie i świat.

\author{
Посмотри - это мы \\ Под скрежещущий гул самолетов \\ Посыпаем разверстые раны \\ золою своих городов, \\ Застываем недвижно у дисков \\ своих пулеметов \\ И над миром гремим литанией \\ бессонных трудов.
}

Просто удивительно, насколько эти пафосные строки, получившиеся у переводчика, отличаются от переводов Вежинского, выполненных впоследствии Натальей Астафьевой, которой удалось сохранить это сдержанное мужество, строгость, решимость, с трудом подавляемое отчаяние.

Впрочем, переводчик Светлана Сомова, не лукавя, сама указала, что это «вольный перевод с польского». Такое признание 
вынуждает меня сказать два слова о границах свободы переводчика, о ее пределах. Насколько точным должен быть перевод? Ведь бывает так, что погоня за синтаксической и словарной точностью как раз не приводит к точности, потому что из-за желания втиснуть в перевод все слова подлинника нарушаются основные синтаксические связи, слова попадают не на свое место, и взамен ясных и точных строф оригинала получается нечто смутное и невыразительное. Как писал великолепный русский переводчик Вильгельм Левик, «точность перевода вообще не может быть мерилом его художественности» ${ }^{4}$. Перевод не должен быть точным, перевод должен быть верным. Мне представляется, что верный перевод в первую очередь адекватно передает поэтическое содержание стихотворения, а не воспроизводит его дословно на другом языке. Поэтическое же содержание очень часто может быть трудно уловимо, особенно когда речь идет о нюансах и оттенках. Так, в финале стихотворения Станислава Балинского «Отчизна Шопена», стихотворения, полного безысходности и отчаяния, вдруг появляется надежда - поэт, который до этого подробно перечислял все несчастья, обрушивающиеся на польских патриотов, словно бы дает нам перевести дыхание и даже поверить в лучшее, однако переводчик, Николай Ашукин, этого словно не чувствует:

Tylko czasami noca, gdy rozpacz Лишь ночами, когда их opada отчаянье мучит упорно,

I gdy Szopen, jak widmo, gra im na Когда призрак Шопена им pianinie, ввуки певучие кинет,

Zjawia się, cała w czerni, staje przy К ним приходит она и стоит nim blada побледневшая, в черном,

I śpiewa do nich cicho - że jest, że У рояля тихонько поет, что nie zginie. жива и не сгинет.

\footnotetext{
4 Вильгельм В. Левик, О точности и верности. Мастерство перевода, Москва 1959, C. 255.
} 
Если в оригинале уровень отчаяния все-таки несколько снижается хотя бы ночью, то в переводе оно по-прежнему «мучает упорно». Ситуация в переводе Ашукина усугубляется еще и тем, что Шопен «кидает» героям свои «певучие звуки», как собаке кидают кость, да и глагольная рифма (явление, считающееся в русской поэзии признаком непрофессионализма) совсем не украшает перевод (в оригинале вполне приличная рифма «pianinie - nie zginie»). В итоге финал, призывающий читателя поверить хотя бы в тень надежды, оказывается не столь убедителен, как в оригинале.

Нужно заметить также, что очень часто слишком вольный перевод свидетельствует о слабости переводчика, нежели о его силе и умении подчинить себе оригинал. Потому что нужно уметь не только подчинять себе оригинал, но и самому подчиняться ему.

Примером того, как некоторые переводческие вольности не затушевывают поэтического содержания оригинала, могут служить представленные в сборнике переводы Марка Живова (сразу оговорюсь, что уровень переводов Живова очень разный). Так, в переводе стихотворения Антония Слонимского «Bcë» («Wszystko») Живов позволяет себе немного отойти от оригинала, сохранив, однако поэтическое содержание. Впрочем, в стихотворении с обильной и строгой рифмовкой некоторые потери абсолютно неизбежны:

Czy w Tuluzie, w Ankarze,

Czy na Węgrzech, w Dakarze,

Czy w Lizbonie, czy w Szkocji wilgotnej,

Czy tu w wielkim Londynie,

Fala niesie nas, płynie -

Coraz dalej od drogi powrotnej.
В Анкаре ли, в Даккаре,

В Глазго, в Мадагаскаре,

В странах дальних, чужих,

незнакомых,

Где 6 нам якорь не бросить,

Штормы гонят, уносят

Нас все дальше и дальше от

дома.

Как видим, в переводе уже нет Тулузы, Лиссабона, Венгрии и Шотландии (роль последней, впрочем, с успехом играет шотландский город Глазго), зато появился экзотический Мадагаскар. 
Bсе это не портит дело, поскольку ощущение того, что героев стихотворения носит по всему свету, сохраняется. Правда, Мадагаскар тут явно притянут для рифмы. Во время войны поляки туда не добрались, зато этот остров был синонимом предвоенных колониальных амбиций II Речи Посполитой.

Во второй строфе переводчик не только усиливает образ странствия, но и снабажает его пышной метафорой, отсутствующей в оригинале:

O co my tak walczymy, Za czymż my tak tęsknimy?

Но за что мы воюем Jakież skarby nam wielkie odjęto? И скорбим о какой мы утрате? Nie o sławę, bogatctwo Не за славы мерцанье Całe nasze tułactwo, Пьем мы горечь скитанья Lecz o sprawę i większą, i świętą. И не ищем добычи богатой.

В оригинале нет яркого образа «пьем мы горечь скитанья», там сказано гораздо сдержаннее - «всё наше бродяжничество» («саłе nasze tułactwo»), однако метафора очень убедительно передает отчаянное странничество героев стихотворения. Жаль только, что из строфы исчезло «sprawa większa i święta» («явление более масштабное и святое»), о которой идет речь в следующих трех строфах стихотворения. Особую сложность этого стихотворения составляет концовка, которая, как мне кажется, переводчику скорее удалась (хотя на этот счет могут быть разные мнения):

Znów popatrzeć przez okno Na kasztany, co mokną, Od dżdżu mokrym przyglądać się listkom.

Iść aleją, przystawać, Dawne ścieżki poznawać. To niewiele, a przecież to wszystko.
Посмотреть в день дождливый На размокшие ивы,

Что печально стоят у дороги. Погулять возле дома По тропинкам знакомым Это всё, а как будто немного.

Замена каштанов на ивы в данном случае только украсило перевод, поскольку для русского уха ивы, как правило, всегда «плакучие», что усиливает элегическое настроение текста 
и отлично попадает в унисон с образом дождя. В последней строке переводчик меняет местами «немного» («niewiele») и «всё» («wszystko»), и тем самым даже немного усиливает финал: последняя строка стихотворения начинается с короткого выдоха «Это всё...», и действительно возникает ощущение, что речь в тексте идет о на самом деле всеобъемлющих вещах, о которых сказано достаточно.

\section{3 .}

Еще один важный аспект искусства перевода, о котором хотелось бы сказать в связи с анализируемым сборником - это понимание переводчиком историко-культурного контекста, в котором создавалось стихотворение, и умение этот контекст передать.

Переводчик не только текстом, но даже подтекстом своих переводов должен дать читателю почувствовать: перед ним именно польский поэт, а не литовский, немецкий или французский. Разумеется, русские поэты-переводчики, находившиеся в эвакуации в Ташкенте, имели очень слабое представление о польском культурно-историческом контексте, о польской ментальности, да и языка они, по болшому счету, не знали.

Многие стихотворения в сборнике носят религиозный характер, что объясняется, во-первых, особой ролью католицизма в польском мировоззрении, а во-вторых, тем, что Польша в годы войны находилась в ситуации, когда помочь может только молитва, а все остальные средства исчерпаны. А советская интеллигенция к 40-м годам прошлого века уже полностью утратила какое-либо понимание евангельского, библейского контекста как писал Петр Вайль, современники Пастернака, читая его строчку «Ты значил всё в моей судьбе...» просто не понимали, кто этот «Ты», о котором шла речь в стихотворениях из «Доктора Живаго». Разумеется, Марк Живов, русский переводчик Балинского, не мог тогда знать, что стихотворение «Wszystko» («Всё») у польского читателя вызывают мгновенные ассоциации

\footnotetext{
5 Пётр Л. Вайль, Стихи про меня, Москва 2011, с. 385.
} 
со стихотворением Норвида «Моя песня». Поэтому, в связи с тем, что вопрос о контекстах в этой ситуации очень сложен, самым удачным переводом в сборнике мне представляется выполненный Анной Ахматовой перевод «Варшавской колядки 1939 года» Станислава Балинского. И не только потому, что Ахматова - великий поэт и замечательный переводчик (к слову, это стихотворение Балинского стало первым переведенным Ахматовой произведением). А еще и потому, что Ахматова уловила состояние польского национального духа времен войны - возможно, в силу тех испытаний, которые выпали на долю поэтессы. Ахматова, как мало кто из русских поэтов, умела находить достоинство в поражении - вот почему перевод «Варшавской колядки» звучит в ее исполнении абсолютно адекватно. Как верно заметил Бродский, «другой язык, будь он трижды славянский, это прежде всего другая психология» ${ }^{6}$. Передача особого польского психологического состояния, в частности, польского катастрофизма, удалось Ахматовой еще и потому, что это состояние было ей отлично знакомо.

А вот слабое понимание контекста (да еще и языка) может сыграть с переводчиком дурную шутку. Так происходит в переводе стихотворения С.Балинского «Отчизна ШІопена», выполненного Николаем Ашукиным. Перечисляя испытания, выпадающие на долю польских патриотов, Балинский пишет:

I dalej znoszą dla niej pod niebem nieszczęścia

Śmiertelny chłód wygnania na mongolskich mrozach,

I w nowe idą piekło, zaciskając pięści,

Na dno upodleń ludzkich w niemieckich obozach.

\section{В переводе:}

За нее переносят, как прежде, под небом суровым,

На монгольских морозах томительный холод изгнанья,

\footnotetext{
6 Яков А. Гордин, Перекличка во мраке. Иосиф Бродский и его собеседники, Санкт-Петербург 2000, с. 140-141.
} 
Подневольно, под окрики, адом измучены новым,

Вместе с войском немецким свершают они злодеянья.

Как видим, в оригинале в последних двух строчках строфы речь идет о поляках, оказавшихся в немецких концлагерях, а в переводе - о коллаборационистах. Разница гигантская, обернувшаяся для перевода катастрофой. Словно почуяв неладное, переводчик сделал еще один, запасной вариант этих двух строчек - что, к сожалению, никак не исправило ситуации:

И бессильные - сжав кулаки, в испытании новом,

Терпят подлость в немецких отрядах, скрывая рыданья.

Скорее всего, что Ашукина подвели так называемые «ложные друзья переводчика», и он неправильно понял смысл слов «obóz» (в данном случае это не «обоз» или «стан», как в случае с устойчивым русским выражением «стан врага», а «лагерь», применительно к этому стихотворению «концентрационный») и «upodlenie» (по-польски это «унижение», но русскому уху чудится, что лирический герой просто становится «подлым»).

\section{4.}

Кроме перевода Ахматовой, самыми болышими переводческими удачами в этом сборнике мне представляются работы Льва Пеньковского. В частности, его переводы стихотворений Казимира Вежинского отличаются высоким уровнем исполнительского искусства (это тот случай, когда искусство переводчика уместно сравнивать еще и с искусством музыкантаисполнителя, так как это тоже творчество на основе чужого материала). Для них характерны почти неукоснительная верность оригиналу и при этом уверенное владение русским стихом. В частности, в переводе стихотворения «Modlitwa za zmarłych w Warszawie» («Молитва за умерших в Варшаве») Пеньковский не только точно передает поэтическое содержание текста, но и делает это с большим артистизмом, демонстрируя, в частности, искусство находить оригинальные рифмы: 
Wieczne odpoczywanie

Racz im dać, Panie (...)
Вечного покоя,

Господи, удостой их! (...)

Много поэтических находок в переводе стихотворения «Pielgrzymom 1940 roku» - эффектные рифмы («необычайным ты отвечай нам»), убедительная концовка («Но когда о расплате вас все-таки в будущем спросят / и за кровь и за труд, и за ваши дороги и тропы, / эти мрачные тени ужель тебя в трепет не бросят, / если подлинно ты за свободу воюешь, Европа»). Высокий уровень Пеньковского-переводчика виден и на примере перевода стихотворения Станислава Балинского «Druga ojczyzna» («Вторая родина»), которое открывает сборник:

Во Франции было сонно, рано темнело над нами. Жили, словно в дремоте, дни шелестели снами.

(...)

И хоть уносятся мысли

В иные дали и шири,

Ее забыть мы не сможем Вторую родину в мире.
We Francji było sennie,

Noce wschodziły wcześnie,

Dnie szeleściły snami,

Żyło się trochę we śnie.

Nie zapomnimy nigdy,

Choć myśl gdzie indziej wzlata.

O tej, co była kiedyś

Drugą ojczyzną świata.

И ахматовский перевод, и переводы Пеньковского отлично иллюстрируют важный тезис, который мне бы хотелось прокомментировать в заключение.

Как верно заметил в свое время Николай Заболоцкий, «хороший поэт может быть плохим переводчиком. [...] Хороший поэт может не иметь склонности к переводам. [...] Но плохой поэт не может быть хорошим переводчиком» ${ }^{7}$ В развитие этого

7 Николай А. Заболоцкий, Заметки переводчика, в: Мастерство перевода, Москва 1959, с. 251. 
тезиса - разумеется, весма дискуссионного - можно сказать, что главной задачей переводчика является создание хорошего стихотворения на национальном языке. Если перевод не читается как хорошее произведение национальной литературы, представителем которой является переводчик - это перевод или очень средний, или просто неудачный. И в этом смысле ведущиеся годами дискуссии о том, является ли переводчик поэзии соперником или же рабом оригинала, преставляются мне довольно умозрительными и излишними. Переводчик поэзии ни то, и ни другое, он соавтор переводимого поэта, поскольку заново воссоздает стихотворение на своем языке при помощи выразительных средств этого языка.

Несмотря на очень разный уровень представленных в «Сборнике польских поэтов» переводов, перед нами, безусловно, уникальный литературный памятник эпохи, к тому же созданный в довольно нетривиальных обстоятельствах. Его ценность заключается для нас еще и в том, что современный переводчик польской литературы может извлечь из него для себя кое-какие выводы, которые могут помочь ему в его работе. Не стоит забывать, что в этой антологии немало шедевров польской поэзии XX века. Кто знает, может быть теперь эти шедевры будут прочитаны и по достоинству оценены российскими любителями польской литературы.

\section{Summary \\ Igor Bielov, "An Anthology of Polish Poetry in Russian \\ Translations", edited by Józef Czapski in 1942, Circumstances Surrounding the Publication of this Anthology and an Analysis of the Translations}

This paper deals with An Anthology of Polish Poets edited by Józef Czapski in 1942 in Tashkent, which has not been published yet. The tools of Translation Studies applied here have allowed to analyse the basic translation problems 
facing the Russian poets when they, on Czapski's request, translated selected examples of Polish poetry.

Igor Biełow - tłumacz literatury polskiej na język rosyjski, stały współpracownik czasopisma „Nowaja Polsza”, juror konkursu Literackiej Nagrody Europy Środkowej „Angelus”. 